\title{
Langmuir 2003, 19, 4856-4858 \\ Photochemical Lithography: Creation of \\ Patterned, Acid Chloride Functionalized \\ Surfaces Using UV Light and Gas-Phase Oxalyl Chloride
}

\author{
G. A. Husseini, T. L. Niederhauser, J. G. Peacock, M. R. Vernon, Y.-Y. Lua, M. C. Asplund,* E. T. Sevy,* and M. R. Linford* \\ Department of Chemistry and Biochemistry, \\ Brigham Young University, Provo, Utah 84602
}

Received November 7, 2002.

In Final Form: February 19, 2003

Organic monolayers ${ }^{1}$ continue to be a subject of active investigation because of their current and potential usefulness in modifying surface properties. Indeed, this utility typically depends on the presence of one or more available functional groups. Functionalized monolayers are often prepared withR, $\omega$-derivatized compounds of the generic formula $\mathrm{Y}\left(\mathrm{CH}_{2}\right)_{n} \mathrm{Z}$, where one of the groups, $\mathrm{Y}$ or $\mathrm{Z}$, binds to the substrate and the other imparts desired functionality. While this approach is frequently successful, the absence of a large number of appropriate bifunctional compounds requires that many desired species must be synthesized, a barrier to those not skilled in the art of organic chemistry. A further issue is possible incompatibilities between end groups. ${ }^{2}$ An alternative path to functionalized surfaces is to first prepare alkyl monolayers from readily available and inexpensive monofunctional precursors, which are then chemically modified through gas- or liquid-phase processes. Examples of such reactions include gas-phase, reduced-pressure photochlorination, ${ }^{2,3}$ photosulfochlorination, ${ }^{4,5}$ fluorination (with atomic F), ${ }^{6}$ and oxidation (with air/UV light, ${ }^{7}$ with an ozone jet and UV light, ${ }^{8}$ and with atomic $\mathrm{O}^{9}$ ). Other similar reports include the interaction of monolayers with H(D) atoms, ${ }^{10}$ low-energy ion beams, ${ }^{11}$ and low-energy electrons. ${ }^{12}$ Surface functionalization has further been demonstrated with solution-phase, free-radical bromination of alkyl monolayers, ${ }^{13}$ photochemical bromination of polyethylene with the subsequent introduction of 4-aminobenzenethiolate functionality, ${ }^{14}$ and the photoconversion of monolayers terminated with thioacetate to sulfonate..$^{15,16}$

Here we present data that indicate that acyl chloride moieties $(-\mathrm{COCl})$ are introduced into and patterned onto methylterminated monolayers through a photoreaction using gas-phase oxalyl chloride $(\mathrm{COCl})_{2}$ and $367 \mathrm{~nm}$ light. This work is significant because activated carboxyl groups, including acid chlorides, are among the most useful in organic synthesis and bioconjugate chemistry. ${ }^{17,18} \mathrm{We}$ also show that the resulting surfaces are amine-reactive. An important advantage of this ch.emistry is that it begins with monolayers prepared from simple, inexpensive monofunctional compounds. It also employs no solvent, uses only one reactive compound, and requires no manifold, vacuum system, or other elaborate equipment or glassware.

This procedure consists of (a) bubbling nitrogen gas through neat oxalyl chloride (bp $64^{\circ} \mathrm{C}$ ) at room temperature, (b) passing the resulting gas stream through a cell that holds an alkyl-monolayer-coated substrate, and (c) illuminating the sample through a quartz window with UV light. The resulting reaction is not entirely surprising s oxalyl chloride is known to absorb $367 \mathrm{~nm}$ light, ${ }^{19}$ and free-radical photo chemical substitution of- $\mathrm{COCl}$ for alkyl hydrogen has been reported in homogeneous, liquidphase systems. ${ }^{20,21}$ And while analogous chemistry should be possible for phosgene $\left(\mathrm{COCl}_{2}\right),{ }^{2}$ this highly toxic gas is more difficult to handle than oxalyl chloride. (The fact that this chemistry works efficiently even after $\mathrm{N}_{2}$ has been bubbled through the oxalyl chloride for extended periods of time suggests that phosgene (bp $8{ }^{\circ} \mathrm{C}$ ), which is a minor impurity in oxalyl chloride, does not play any important role in the observed surface functionalization.) Simple patterning experiments were performed using either a metal foil or a metal mesh as contact masks. Areas that are exposed to light are functionalized, giving a hydrophilic surface, while unexposed areas are not functionalized and remain hydrophobic.

Alkyl monolayers that were exposed to UV light and gaseous oxalyl chloride were prepared by silanizing native oxidecoated $\mathrm{Si}(100)$ with neat, heated chlorodimethyloctadecylsilane. ${ }^{22}$ This method produces fairly thin $(\sim 10 \AA)$ films with advancing water contact angles of $\sim 100^{\circ}$. These data suggest that there is a significant amount of methylene character to the mono layers and that their alkyl chains are highly tilted. ${ }^{1}$ Following exposure to oxalyl chloride and $367 \mathrm{~nm}$ light, we observe the following changes in monolayer properties: (1) The advancing/ receding water contact angles decrease from $99^{\circ} / 84^{\circ}$ to $66^{\circ} / 26^{\circ}$. (2) The ellipsometric thickness of the monolayer

This document is the Accepted Manuscript version of a Published Work that appeared in final form in Langmuir, copyright @ American Chemical Society after peer review and technical editing by the publisher. To access the final edited and published work see https://doi.org/10.1021/la020896g 

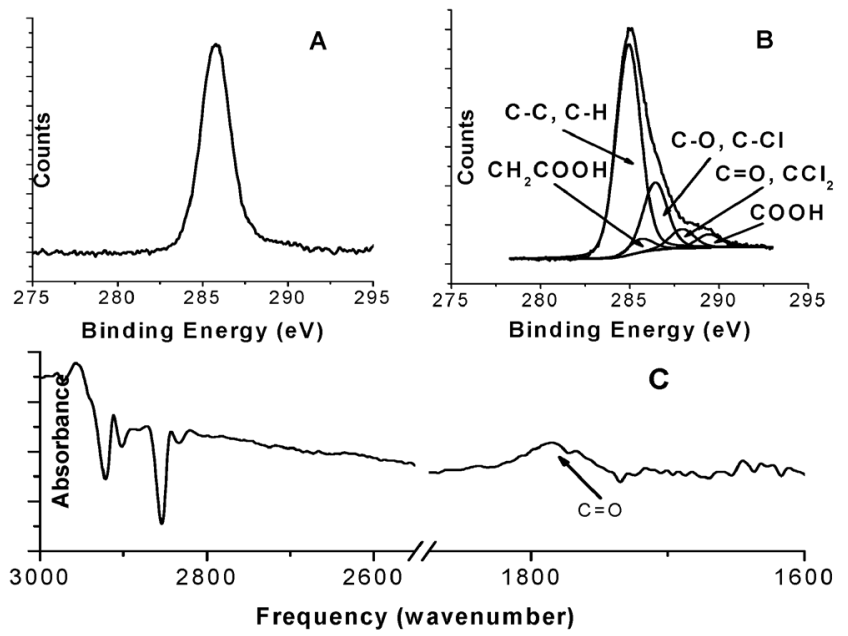

Figure 1. XPS and IR spectra of an alkylated $\mathrm{Si}(100)$ wafer after exposure to oxalyl chloride and $367 \mathrm{~nm}$ light. C 1s narrow XPS scan (A) prior to reaction and (B) after reaction and immersion in dilute acetic acid. (C) Transmission IR spectrum from a double-polished Si(111) wafer, which was silanized on both sides. Only half of the surface was exposed to $(\mathrm{COCl})_{2}$ and $367 \mathrm{~nm}$ light. Spectra from the functionalized and unfunctionalized regions were ratioed to give the data shown here. Note peaks characteristic of CdO at $\sim 1780 \mathrm{~cm}^{-1}$ and the bleaching of $\mathrm{CsH}$ at 2850 and $2920 \mathrm{~cm}^{-1}$.

nearly doubles, increasing by $\sim 10 \AA$. (3) The XPS survey spectrum shows significant increases in the carbon and oxygen signals and substantial $\mathrm{Cl} 2 \mathrm{p}$ and $\mathrm{Cl} 2 \mathrm{~s}$ signals. (4) The XPS C 1s narrow scan shows significant quantities of carbon that is chemically shifted. (5) Time-of-flight secondary ion mass spectrometry (ToF-SIMS) shows fragments that correspond to $\mathrm{COCl}^{+}, \mathrm{CH}_{2} \mathrm{COCl}^{+}$, and $\left(\mathrm{CH}_{2}\right)_{2} \mathrm{COCl}^{+}$. (6) Transmission FTIR spectroscopy, which uses an untreated monolayer surface as a reference, shows a loss of CsH stretches and a new peak in the $\mathrm{CdO}$ stretching region.

First, the decrease in water contact angles is consistent with the introduction/addition of hydrophilic groups into the monolayer. Second, the significant increase in ellipsometric thickness is consistent with the addition of numerous heavy atoms to the monolayer and a straightening of its alkyl chains (a decrease in their tilt angles). Third, the increase in $\mathrm{C}$ and $\mathrm{O}$, and appearance of $\mathrm{Cl}$ signals by XPS in the monolayer are consistent with a substitution reaction of $H$ for heavier atoms (the uncorrectedC1s/Si2p,O1s/Si2p,andCl2s/Si2pratiosincrease from 1.2 ( 0.1 to 2.3 ( 0.2, from 2.3 ( 0.2 to 3.7 ( 0.2 , and from 0 to 1.3 ( 0.5 , respectively).

Fourth, the multiple, chemically shifted components that appear in the C 1s XPS narrow scan (see Figure 1) indicate multiple oxidation states for carbon. Most important is a peak that is shifted $\sim 4.5 \mathrm{eV}$ from the main carbon signal that is attributed to acid chloride/carboxylic acid groups. ${ }^{23}$ As expected, this peak is found both after reaction with oxalyl chloride (-COCl) and after the resulting monolayers are immersed in dilute acid for $1 \mathrm{~h}(-\mathrm{COOH})$. In Figure $1 \mathrm{~B}$ this component accounts for $4.3 \%$ of the total area of the $\mathrm{C} 1 \mathrm{~s}$ narrow scan. This is a significant fraction, as each silane precursor to the monolayer contains 20 carbons. The other two peaks in the $\mathrm{C} 1 \mathrm{~s}$ narrow scan at +1.5 and $+3.0 \mathrm{eV}$, from the main carbon peak, are attributable to carbon bonded either once or twice to oxygen or chlorine.(It is both fortuitous, because it makes peak fitting more straightforward, and unfortunate, because some ambiguity is introduced into the data, that chemical shifts induced by oxygen and chlorine on carbon are essentially equal $(\sim 1.5 \mathrm{eV})$.

Fifth, the ToF-SIMS data are consistent with the formation of acid chloride moieties in the monolayer after exposure to oxalyl chloride. Sixth, transmission IR spectroscopy, which has been successfully used to study monolayers, ${ }^{24}$ is consistent with substitution of hydrogen by other chemical groups note the negative peaks in the $\mathrm{C}-\mathrm{H}$ stretching region that correspond to the symmetric and asymmetric methylene stretches, signaling the loss of this group. (The change in absorbance was calculated by taking the log of the ratio of the exposed to the unexposed surface.) The loss of C-H intensity may also indicate some cross-linking of the monolayers. ${ }^{24-27}$ The peak at $1780 \mathrm{~cm}^{-1}$ in Figure 1c has about the same width $\left(\sim 100 \mathrm{~cm}^{-1}\right)$ as the carbonyl band in IR spectra of other materials. ${ }^{28}$

A series of control experiments were also performed with this system. For example, no change in the XPS spectrum of bare silicon/silicon oxide is noted when it is exposed to oxalyl chloride and $367 \mathrm{~nm}$ light. In addition, no significant differences in contact angles, ellipsometric thicknesses, or XPS spectra were found before and after alkyl monolayers were exposed to either $367 \mathrm{~nm}$ UV light alone or oxalyl chloride in the dark. 
In summary, these data suggest that complex reactions occur between the monolayer and illuminated oxalyl chloride that introduce significant amounts of material into the monolayer, some of which is the desired reactive functional group (-COCl).

Because the functionalization is photoinduced, it is possible to control the location of the - $\mathrm{COCl}$ addition to the surface. For example, when half of a silanized (hydrocarbon) monolayer surface is covered with aluminum foil during the photoreaction, the physical properties of the covered region remain the same, and water prefers the exposed region. Similarly, if a metal mesh, either with or without a $50 \mu \mathrm{m}$ Teflon spacer, is placed on the surface during the reaction, the grid pattern is transferred to the surface.

Because the $-\mathrm{COCl}$ group is amine reactive, an important test of the funtionalization of the surface is its subsequent reaction with an amine. For these experiments, monolayers of 1-hexadecene on scribed Si were employed. ${ }^{29,30}$ The alkyl chains in these monolayers are believed to be bonded through $\mathrm{C}$-Si bonds, which are much less succeptable to hydrolysis than the Si-O linkages found in monolayers prepared from mono chlorosilanes. In these experiments monolayers on scribed silicon were immersed for $1 \mathrm{~h}$ in a $1 \mathrm{mM}$ (monomer) solution of polyethylenimine after (a) monolayer formation; (b) photoreaction with oxalyl chloride; and (c) photoreaction, immersion in water for $1 \mathrm{~h}$, and rinsing with water and drying. The methyl-terminated monolayer showed moderate to low quantities of nitrogen ( $\mathrm{N}$ 1s/Si $2 \mathrm{p}$ ) 0.19) and strong carbon signal (C 1s/Si $2 \mathrm{p}$ ) 1.5). The surface that was immediately immersed in the polymer solution contained much stronger nitrogen and carbon signals $(\mathrm{N} 1 \mathrm{~s} / \mathrm{Si} 2 \mathrm{p}$ ) 1.7 ( 0.3, C 1s/Si 2p ) 3.1 ( 0.3 ), suggesting covalent attachment of the polymer. The surface that was first immersed in water to allow hydrolysis of -COCl to $-\mathrm{COOH}$ showed lesser but still significant increases in surface nitrogen and carbon $(\mathrm{N} 1 \mathrm{~s} / \mathrm{Si} 2 \mathrm{p}) 0.7(0.1, \mathrm{C} 1 \mathrm{~s} / \mathrm{Si} 2 \mathrm{p}) 1.9(0.2)$. These latter results are consistent with surface hydrolysis followed by polymer adsorption due to electrostatic interactions between surface carboxylates and positively charged groups on the polymer. ${ }^{31}$

Preliminary results for photochemical bleaching of gasphase oxalyl chloride show clear evidence for photodissociation. Gas-phase samples were first exposed to the $355 \mathrm{~nm}$ output of a Nd:YAG laser followed by monitoring of the IR spectrum using FTIR. Infrared spectra clearly display a decrease of the $\mathrm{C}-\mathrm{C}$ bond signal near $1060 \mathrm{~cm}^{-1}$, indicating the breaking of the $\mathrm{C}-\mathrm{C}$ bond. $\mathrm{C}-\mathrm{C}$ bond signals continued to decrease with increased UV exposure while

other oxalyl chloride spectroscopic features remained constant. Time-resolved gas-phase experiments remain to be performed to measure a quantitative photodissociation quantum yield at $355 \mathrm{~nm}$ as well as the structure of the oxalyl chloride photoproduct. Nevertheless, these preliminary results reconfirm ${ }^{19}$ the existence of photochemistry at $355 \mathrm{~nm}$.

In conclusion, we have presented preliminary data that suggest the introduction of -COCl groups into alkyl mono layers by a photo reaction with oxalylchloride. Future work with this system will focus on better understanding the effect of wavelength on surface reactivity, improving surface patterning through more sophisticated masks and optics, studying the reactivity of the surface with small molecules, functionalizing different $\mathrm{C}$-H containing polymer surfaces, and lowering the yield of byproducts on the surface.

Supporting Information Available: Reaction conditions, related data, pictures of patterned surfaces, and a description of instrumentation. This material is available free of charge via the Internet at http://pubs.acs.org

(1) Ulman, A. An Introduction to Ultrathin Organic Films from Langmuir-Blodgett to Self-Assembly; Academic Press: Boston, MA, 1991.

(2) Linford, M. R.; Chidsey, C. E. D. Langmuir 2002, 18, 6217-6221.

(3) Maoz,R.OrganicReactionsofOrganizedMonomolecularSystems Adsorbed on Solid Substrates.

Thesis/Dissertation, Weizmann Institute of Science, 1985.

(4) Cicero,R.L.;Wagner,P.;Linford,M.R.;Hawker,C.J.;Waymouth,

R. M.; Chidsey, C. E. D. Polym. Prepr. 1997, 38, 904-905.

(5) Wagner, P.; Nock, S.; Spudich, J. A.; Volkmuth, W. D.; Chu, S.; Cicero, R. L.; Wade, C. P.; Linford, M. R.; Chidsey, C. E. D. J. Struct. Biol. 1997, 119, 189-201.

(6) Robinson, G. N.; Freedman, A.; Graham, R. L. Langmuir 1995, 11, 2600-2608.

(7) Ye, T.; Wynn, D.; Dudek, R.; Borguet, E. Langmuir 2001, 17, 4497-4500.

(8) Moon, D. W.; Kurokawa, A.; Ichimura, S.; Lee, H. W.; Jeon, I. C.

J. Vac. Sci. Technol., A 1999, 17, 150-154.

(9) Paz, Y.; Trakhtenberg, S.; Naaman, R. J. Phys. Chem. 1992, 96, 10964-10967.

(10) Kluth, G. J.; Sung, M. M.; Maboudian, R. Langmuir 1997, 13, 6491-6496.

(11) Winger, B. E.; Julian, R. K., Jr.; Cooks, R. G.; Chidsey, C. E. D.

J. Am. Chem. Soc. 1991, 113, 8967-8969.

(12) Olsen, C.; Rowntree, P. A. J. Chem. Phys. 1998, 108, 37503764.

(13) Baker, M. V.; Watling, J. D. Tetrahedron Lett. 1995, 36, 46234624.

(14) Chanunpanich, N.; Ulman, A.; Strzhemechny, Y. M.; Schrarz, S. A.; Janke, A.; Braun, H. G.;

Kraztmuller, T. Langmuir 1999, 15, 2089-2094.

(15) Collins, R. J.; Sukenik, C. N. Langmuir 1995, 11, 2322-2324.

(16) Collins, R. J.; Shin, H.; DeGuire, M. R.; Heuer, A. H.; Sukenik,

C. N. Appl. Phys. Lett. 1996, 69, 860-862. 
(17) March, J. Advanced Organic Chemistry; John Wiley \& Sons: New York, 1992.

(18) Hermanson, G. T. Bioconjugate Techniques; Academic Press: San Diego, CA, 1996.

(19) Baklanov, A. V.; Krasnoperov, L. N. J. Phys. Chem. A 2001, 105, 97-103.

(20) Bashir-Hashemi, A.; Doyle, G. Aldrichimica Acta 1996, 29, 4349.

(21) Bashir-Hashemi, A.; Li, J.; Gelber, N.; Ammon, H.J. Org. Chem. 1995, 60, 698.

(22) Frydman, E.; Cohen, H.; Maoz, R.; Sagiv, J. Langmuir 1997, 13, 5089-5106.

(23) Baptiste,A.;Gibaud,A.;Bardeau,J.F.;Wen,K.;Maoz,R.;Sagiv,

J.; Ocko, B. M. Langmuir 2002, 18, 3916-3922.

(24) Maoz, R.; Sagiv, J. J. Colloid Interface Sci. 1984, 100, 465-496.

(25) Maoz, R.; Netzer, L.; Gun, J.; Sagiv, J. J. Chim. Phys. Phys.Chim. Biol. 1998, 85, 1059-1065.

(26) Jordan, K.; Iroh, J. O. Polym. Eng. Sci. 1996, 36, 2550-2555.

(27) Niederhauser, T. L.; Jiang, G.; Lua, Y.-Y.; Dorff, M. J.; Woolley, A. T.; Asplund, M. C.; Berges,

D. A.; Linford, M. R. Langmuir 2001, 17, 5889-5900.

(28) Niederhauser,T.L.;Lua,Y.-Y.;Jiang,G.;Davis,S.D.;Matheson, R.; Hess, D. A.; Mowat, I. A.;

Linford, M. R. Angew. Chem., Int. Ed.

(29)

(30) Husseini, G. A.; Zilch, L. W.; Sevy, E. T.; Asplund, M. C.; Linford, M. R. Surf. Sci. Spectra 2001, 8, 274-283. 
(31) (23) Practical Surface Analysis; Biggs, D., Seah, M. P., Eds.; Wiley:

(32) Chichester, U.K., 1990.

(33) (31) Decher, G.; Hong, J.-D.; Schmitt, J. Thin Solid Films1992, 210/ 211, 831. 